Send your letters to the editor, British Dental Journal, 64 Wimpole Street, London W1G 8YS E-mail bdj@bda.org

Priority will be given to letters less than 500 words long. Authors must sign the letter, which may be edited for reasons of space

\section{Outside the box}

Sir, it is rare to read a paper as inspiring and beautifully illustrated as Anterior dental aesthetics: Historical perspective (BDJ 2005; 198: 737-742).

Dental (and medical) students are often selected on narrow scientific grounds alone. They are then encouraged to provide evidence-based dentistry, although much of the evidence is of limited value to the long term management of patients with chronic diseases, such as periodontitis. This leads to a significant risk of inappropriate and over-treatment involving animal-derived products, antibiotics and antiseptics as well as surgical techniques. The massive funding required for multicentric randomised clinical trials over sufficiently long periods of time, inhibit the discovery of what is most needed.

Appropriate long term health provision requires practitioners to apply fundamental principles and think 'outside the box' just as Dr Ahmad has done.

To truly educate, using the values of art, mathematics, philosophy, architecture, physics, chemistry, history of ancient civilisations and psychology rather than science alone, as in this excellent paper, makes dentistry a rewarding experience for providers and recipients.

I had feared that the loss of characters like John Besford for inspiration in dental education with politically safe alternatives would mean a poorer future for our profession. I feel assured by this marvellous paper and I look forward very much to the remainder of this series.

\section{Gibson}

\section{Southampton}

doi: 10.1038/sj.bdj.4812702

\section{New PDS contracts}

Sir, there is a lot of activity on the part of Primary Care Trusts to encourage general dental practitioners to sign up to the new PDS contracts. Surprise is expressed that so few dentists are keen to do so. I am writing to explain, in a few words, why we are so reluctant. When the NHS was created in about 1947, the doctors were bought in to the NHS system by the government of the day buying out the goodwill of every medical practice. The phrase 'I have stuffed the doctors' mouths with gold' was alleged to have been used by (correct me if I'm wrong) Nye Bevan to describe how he persuaded the medics to join the system. That was never done to the dentists, and we still own our own goodwill - ie patient lists - and I believe even an NHS list still has some small value. What is iniquitous about the new contract on offer is that it takes away the goodwill; the PCT appropriates the list of patients without payment, and gives nothing in return for it other than the potential loss of self-employed status on the part of every subscribing dentist. In some spheres of business this action would be described as fraud or theft. I do not want my mouth 'stuffed with gold' but if I am to give up, voluntarily, control of my whole business I want to be properly rewarded - there has to be a sale, not a robbery.

\section{S. W. White \\ Bristol}

doi: 10.1038/sj.bdj.4812703

\section{Doubtful dental policies}

Sir, there have been several issues raised in the media which cast doubt on to current dental policies and strategies. The popular dental press has been advising of recent promotions to recruit dentists from overseas. In particular, many will be aware of the drive to enlist Polish dentists to prop up the deemed flagging dental service. I am sure that few people have problems with the concept of any qualified overseas dentists legitimately in Britain. I am curious to know whether the think tank at the source of the campaign have considered implications to the host nations of the recruits. Very recently, criticism of overseas nurses from Nigeria

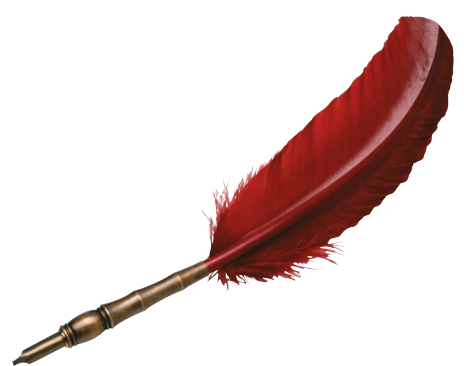

working in hospitals in Britain has been noted. This practice has drained the countries of skilled workers and placed their own population in a more vulnerable position in terms of healthcare. I wonder whether we, as a profession, could be facing a political time-bomb.

It is also poignant that an estimated third of British medical graduates may face difficulties in securing a new post. The medical and dental professions obviously work separately, however it does seem nonsense that we have a deficit on the one hand and a surplus on the other.

R. Atkinson

Reading

doi: 10.1038/sj.bdj.4812704

\section{Ultrasound warning}

Sir, I thought I should contact the $B D J$ regarding a possible concern which has recently been brought to my attention.

It involves the use of ultrasonic scaling instruments on patients whose severe epilepsy is controlled by use of a vagal nerve stimulator.

The firm which makes these advise against the use of any treatment involving therapeutic ultrasound as there is a theoretical risk that this could damage the pulse generator in the stimulator.

M. Dennett

Leeds

doi: 10.1038/sj.bdj.4812705

Double standard

Sir, Dr Clewett (BDJ 2005; 199: 67) criticises the BDA and the BDHF for not producing patient information in languages other than English. Surely people coming to live and work in this country have a duty to learn English, just as people living and working in other countries are expected to learn the local language.

C. F. Martin

Yorkshire

doi: $10.1038 /$ sj.bdj.4812706 


\section{Surgical specialist lists}

Sir, is the GDC failing in its duty to protect the public by currently accepting the Oral and Maxillofacial Surgical (OMFS) Certificate of Completion of Specialist Training (CCST) for entry onto the Oral and Surgical Dental Specialist lists? The Specialist Advisory Committee at its recent inspection of our Spr training was correctly informed that our unit's Spr was not involved with our dentoalveolar surgical lists, no doubt little different to other units' Spr training. I have been concerned for some time that OMFS training seems to neglect dentoalveolar surgical training but I accept that such exposure must vary throughout the UK, yet all are given entry to the GDC surgical specialist lists on receipt of the CCST in OMFS. Is it now not appropriate for the GDC to review this process of entry on to these lists? Should the GDC not require proof that those on their specialist surgical lists currently undertake the surgery as the lists imply expertise? These lists have implications that those on them are appropriately trained and currently experts. The GDC should consider these issues to ensure that their surgical specialist lists are meaningful to the general public.

G. D. Wood

By email

doi: 10.1038/sj.bdj.4812707

\section{NHS envy}

Sir, following the trends of Canadian pop stars and Hollywood directors, I have recently moved to New Zealand. Not, I might add, for a desire to partake in the world's highest bungee jump, or further my interest in rugby or sheep. Rather a change of lifestyle, to see how dentistry can be away from a practice in the north of England: away from working under the auspices of the NHS, seen now as a treadmill but once the envy of the world.

The winds of change have blown in both directions. The scenery is as wonderful as Peter Jackson depicts, but the quality of the roads is playing havoc with the suspension. The beaches are beautifully deserted, despite the volcanic sand being black, and to my eyes, dirty. Food and drink are much cheaper, although there are still the same fluoridation arguments in the popular press. The paperwork is very different, although the teeth are still the same - or are they?
Anecdotal evidence as we know is the lowest form of evidence (but the highest form of communication?) but anecdotally, the teeth here are worse than the teeth in Wakefield. I still see middle class teenagers with gleaming ivory arches that would put Julia Roberts to shame, but at the other end of the spectrum things are not so white. Often in Yorkshire I would have to talk patients through the choices of 'Rolls Royce dentistry' (super high impact injection moulded dentures with Vivodent teeth), or 'VW Golf dentistry' (NHS standard acrylic gnashers). Whichever the patient chose, the food still got from A to B. Here, in an area (empirically) similar to my previous work place, the choice seems to be more 'engine' (restore a posterior tooth) or 'bodywork' (restore an anterior tooth), or even sometimes just nothing; if you don't have the cash, you don't get the teeth. Public funding for dentistry here is almost non-existent, unless a painful tooth is to be extracted, in which case a part payment is made by the health body. Not so much a safety net for the disadvantaged, but an un-inflated life jacket. The NHS I knew in England is still the envy of the world.

Those dentists back home who believe that there should be such a safety net (and a society has been said to be judged by how it treats those who are less able to help themselves) are being given the opportunity now to create a new service to serve the public. I hope they can make it one that is the envy of Britain too.

\section{E. Hitchings}

Tauranga, New Zealand

doi: 10.1038/sj.bdj.4812708

\section{Proposed NHS charges}

Sir, I have just been reading the review of the proposed National Health Service dental treatment charges.

Just suppose that a supermarket sold dental treatment items and you knew that you could buy the basic two examination and scale and polish - for $£ 15$, but that if you put another single item in your shopping trolley - even the most trivial buccal pit amalgam filling - then the bill was going to rocket to $£ 41$, which is a full day's take home pay for quite a lot of people... Then what would you think of that store's pricing policy?

\section{J. Hartley}

Peterborough

doi: 10.1038/sj.bdj.4812709 